\title{
BMJ Open Longitudinal cohort study describing persistent frequent attenders in Australian primary healthcare
}

\author{
Carly Pymont, Peter Butterworth
}

To cite: Pymont $\mathrm{C}$, Butterworth P. Longitudinal cohort study describing persistent frequent attenders in Australian primary healthcare. BMJ Open 2015;5:e008975. doi:10.1136/bmjopen-2015008975

- Prepublication history for this paper is available online. To view these files please visit the journal online (http://dx.doi.org/10.1136/ bmjopen-2015-008975).

Received 3 June 2015 Revised 31 August 2015 Accepted 8 September 2015

CrossMark

Psychiatric Epidemiology and Social Issues Unit, Centre for Research on Ageing, Health \& Wellbeing, Research School for Population Health, Australian National University, Canberra, Australia

Correspondence to Dr Carly Pymont; carly.pymont@gmail.com

\section{ABSTRACT}

Objectives: To describe patterns of frequent attendance in Australian primary care, and identify the prospective risk factors for persistent frequent attendance.

Design, setting and participants: This study draws on data from the Personality and Total Health (PATH) Through Life Project, a representative community cohort study of residents from the Canberra region of Australia. Participants were assessed on 3 occasions over 8 years. The survey assessed respondents' experience of chronic physical conditions, self-reported health, symptoms of common mental disorders, personality, life events, sociodemographic characteristics and self-reported medication use. A balanced sample was used in analysis, comprising 1734 respondents with 3 waves of data. The survey data for each respondent were individually linked to their administrative health service use data which were used to generate an objective measure of general practitioner (GP) consultations in the 12 months surrounding their interview date.

Main outcome measures: Respondents in the (approximate) highest decile of attenders on number of GP consultations over a 12-month period at each time point were defined as frequent attenders (FAs).

Results: Baseline FAs (8.4\%) were responsible for $33.4 \%$ of baseline consultations, while persistent FAs $(3.6 \%)$ for $15.5 \%$ of all consultations over the 3 occasions. While there was considerable movement between FA status over time, consistency was greater than expected by chance alone. While there were many factors that differentiated non-FAs from FAs in general, persistent frequent attendance was specifically associated with gender, baseline reports of depression, self-reported physical conditions and disability, and medication use.

Conclusions: The degree of persistence in GP consultations was limited. The findings of this study contribute to our understanding of the risk factors that predict subsequent persistent frequent attendance in primary care. However, further detailed investigation of longitudinal patterns of frequent attendance and consideration of time-varying determinants of frequent attendance is required.

Across the Organisation for Economic Co-operation and Development (OECD),

\section{Strengths and limitations of this study}

- Use of rich survey data describing the sociodemographic, interpersonal, health and personality characteristics of participants linked to each individual's national health insurance scheme service use record to examine frequent attendance without sampling or self-report bias.

- Eight years of data to identify the characteristics and patterns of frequent attenders over time.

- Unable to examine temporal ordering and potentially the causal nature of the relationships.

- Restricted to a mid-aged cohort in the Canberra region of Australia.

- While the use of linked Medicare data provides an objective marker of health service use, it does not cover all potential primary care consultations (eg, excluding Department of Veterans' Affairs beneficiaries and some patients receiving services under compensation agreements).

there is increasing policy focus on the sustainability of healthcare costs in the context of population ageing. ${ }^{12}$ In Australia, this has led to a focus on individuals' level of health service use and proposals to introduce mandatory copayments as a price signal to deter potential unnecessary overuse of health services, including general practitioner (GP) services. $^{3} 4$ The validity of these concerns that frequent attendance reflects unnecessary overuse of health services has received limited attention in the Australian literature though there is a growing body international research examining factors associated with frequent use of health services. ${ }^{56}$

Our focus in this study is on patients with high consultation rates with their GP. The existing international research shows, for example, that the top $3 \%$ of attenders at primary health services account for around $15 \%$ of all consultations. ${ }^{7}$ Additionally, these frequent attenders (FAs) generate five times as many prescriptions and hospital contacts as less FAs. ${ }^{8}$ FAs 3-year expenditures have been found to be higher than non-FAs even 
after adjustment for confounders such as their poorer health. ${ }^{9}$ Data from Australian's national universal health insurance scheme (Medicare) in 2012-2013 show the top $12.5 \%$ of GP attenders accounted for $41 \%$ of (nonhospital) Medicare expenditure. ${ }^{10}$

However, a variety of definitions of FAs are used in the literature. Some studies use an absolute criterion, defining FAs by a minimum cut-point of consultations, commonly between $6^{11}$ and 12 in a single year. ${ }^{10}{ }^{12}$ Others ${ }^{5} 91314$ use a relative definition, focused on the top $10 \%$ of attenders over a 12-month period, often stratified by sex and age.

The elevated levels of GP consultations may simply reflect greater patient morbidity, with FAs having more chronic conditions and more complex health needs than non-FAs. ${ }^{10}$ However, Foster et $a l^{15}$ concluded that there remains individual variability in GP consultations which is independent of morbidity or medical conditions. Sociodemographic characteristics are relevant, with FAs more likely to be elderly women, those who are socioeconomically disadvantaged, ${ }^{12}$ unemployed or not active in the workforce, ${ }^{16}$ or an immigrant. ${ }^{17}$ Indeed Vedsted and Olesen ${ }^{18}$ found that even after adjusting for health that living alone and unemployment were predictors of frequent attendance for men. Additionally psychological and psychiatric factors are important with FAs not only more likely to report psychological distress, ${ }^{19}$ depressive and somatoform disorders, ${ }^{16}$ but also show elevated health anxiety and hypochondriacal beliefs. ${ }^{20} 21$

There has been less consideration of the consistency in classification as a FA over time. A 20-year retrospective study found the majority of those identified as a FA reverted to normal consulting patterns within 5 years, with the strongest predictor of consistent high attendance being multiple morbidity. ${ }^{22}$ Smits $e t a l^{23}$ found that persistent FAs, compared with those who were FAs at only one time point, experienced more social problems, psychiatric problems (and received more prescriptions for psychotropic medication) and medically unexplained physical symptoms, in addition to more chronic disorders (especially diabetes). Subsequent research ${ }^{21}$ found that panic disorder, anxiety, stressful life events, illness behaviour and lack of mastery were each associated with persistent frequent attendance.

Despite FAs being central to policy proposals seeking to reduce potential overuse and unnecessary service use, little is known about FAs in the Australian primary care setting. Using patient self-report data on service use and GP reports of patient morbidity collected as one aspect of the BEACH study, Knox and Britt ${ }^{24}$ found that frequent attendance was associated with back pain, holding a concessional healthcare card, remoteness, and anxiety and depression. The recent Australian National Health Performance Authority report ${ }^{10}$ confirmed the greater morbidity among primary care FAs, who also reported elevated levels of specialist and Medicare covered consultations, and emergency department and hospital admissions. Further, there is evidence that the context provided by country of study may strongly influence the profile of FAs, with a recent study in Slovenia finding that FAs were more likely to be men and that anxiety, depression and age were not associated with attendance: results that diverge from much of the previous research conducted elsewhere.

Methodological limitations are evident in much of the existing research of FAs. A large portion of international studies (and all Australian studies identified) are crosssectional and therefore unable to examine persistence of frequent attendance over time. The studies that reported analysis of administrative data often lack detailed information on individual patient characteristics, while survey data rely on retrospective patient reports of service use. Apart from those studies conducted in countries where enlistment of patients with specific GP practices provides a known denominator for analysis, ${ }^{21}$ studies based on patient samples recruited through primary care in countries such as Australia may lack representativeness, potentially excluding nonattenders (estimated as $15.3 \%$ of Medicare eligible population in any year $)^{10}$ or oversampling FAs if recruitment is based on service encounters.

Recently, however, Smits $e t a l^{21}$ examined persistent FAs using GP data and survey questionnaires. They found a range of independent predictors of persistence in attendance including anxiety disorder, negative life events, illness behaviour and lack of mastery. However, as they note, the sampling could have led to overrepresentation and they were unable to include measures of perceived health status or quality of life. Further persistence was assessed over 2 years, and so cannot inform about persistence over a longer period.

The current study seeks to extend the previous literature by reporting analysis of a community-based sample of mid-aged Australians followed over three waves/ 8 years. In addition to rich survey data describing the sociodemographic, interpersonal, health and personality characteristics of participations, the survey data are linked to each individual's national health insurance scheme service use record. This provides a unique opportunity to identify the characteristics and patterns of FAs over time, and provide an evidence base to better inform planning and policy development in this important but controversial area. We aim to identify the risk factors (identified from previous research) which are associated with frequent attendance in an Australian sample and determine the factors that may differentiate non-FAs from occasional and persistent FAs. Owing to the current lack of Australian research, we take a broad approach to this examination and include a range of factors identified above.

\section{METHODS}

Design

This study draws on data from the Personality and Total Health (PATH) Through Life Project, a longitudinal 
community study of health and well-being. The data, methods, and individual scales and measures are described in detail elsewhere ${ }^{25}$ but briefly: the PATH project follows three narrow age range cohorts, randomly sampled from the electoral rolls for Canberra and Queanbeyan and reassessed every 4 years. Enrolment on the electoral roll is compulsory in all but the most exceptional circumstances. ${ }^{25}$ This analysis considers data from three time points for the mid-aged cohort who were born between 1956 and 1960. There were 2530 participants who completed the baseline interview in 2000 (a response rate of 65\%). The attrition rate is low, with $93 \%$ of respondents reassessed at wave 2 (in 2004), and $86 \%$ of initial participants reassessed at wave 3 (in 2008).

Respondents were assessed by a trained interviewer, usually in their own home or at the Australian National University. At each wave, participants completed selfreport measures on a laptop computer and the interviewer administered a battery of physical and cognitive tests. Participants were asked to consent to release administrative (Medicare) data on their health service use for a 2-year period surrounding their interview date. Linkage was conducted by the Health Insurance Commission based on each individuals own unique Medicare Number which was supplied by respondents. The consent rates to data linkage across the three waves ranged from $92 \%$ to $96 \%$.

At each wave, respondents provided written informed consent.

\section{Measures}

The individually linked Medicare data were used to calculate the number of GP consultations for each respondent in the 12 months surrounding the date of each individual's interview (6 months prior and post). A comprehensive list of relevant GP Medicare item numbers (service encounters for which a fee is payable) was generated for each wave. This represents all face-to-face services delivered by a GP and funded through the national universal health insurance scheme including consultations, chronic disease management, assessments, immunisation, screening, psychological treatment and after hour consultation, etc. It does not include services delivered by other medical professionals, nurses, or specialists or services delivered in a hospital setting. For each wave, a cut-point was applied to identify the (approximately) $10 \%$ of respondents with the greatest number of GP consultations. This corresponds to nine or more consultations within the 12-month reference period for each wave. Age adjustment was not necessary given the restricted age range of the cohort.

A comprehensive range of covariates, available in each wave of the survey, were selected on the basis of previous literature.

- Morbidity: Participants were asked if they experienced a range of chronic physical conditions (heart disease, cancer, arthritis, thyroid disorder, epilepsy, cataracts, asthma, diabetes and stroke).

- Perceived health: Individual items from the Short Form Health Survey (SF-12) ${ }^{26}$ assessed self-rated health, health-related impairment in daily activities and work, and pain.

- Health anxiety and depression: The Goldberg Anxiety and Depression scales were included in all three waves of the PATH survey and assess respondents experiences over the past month. ${ }^{27}$ The nine-item depression scale was used as a measure of severity (the number of symptoms experienced: 0-9). Individual items from the Anxiety scale were used as measures of aspects of health anxiety, including reported experience of (1) headaches, (2) trembling, (3) sleep issues and (4) worry about health.

- Control/mastery: Mastery or sense of control over one's environment has been found to be inversely associated with frequent attendance ${ }^{21}$ and was assessed at each wave using Pearlin $e t a l \mathrm{~s}^{28}$ seven-item scale. Items included 'I have little control over the things that happen to me' and 'I can do just about anything I really set my mind to do'. Responses are on a four-point Likert type scale from 1 (strongly agree) to 4 (strongly disagree). Items were summed, so a higher score indicated greater sense of mastery.

- Ruminative style: Repetitive focus on negative thoughts was assessed via the 10 -item version of the Rumination Responses Scale. $^{29}$

- Life events: Previous studies have demonstrated an association between frequent attendance and the experience of adverse life events. ${ }^{21}$ In PATH, participants' experience of stressful life events in the past 6 months was assessed with a scale based on Brugha and Cragg $^{30}$ and considered events such as family injury or illness, death of friends/family, relationship dissolution, career crisis or threat of unemployment (excluding personal health).

- Sociodemographic characteristics: Consistent with the previous literature, a range of sociodemographic measures assessed in PATH were incorporated in the current analysis including labour force status, educational achievement (higher education, completed high school vs not), dependent children aged under 15 years, and the experience of financial strain. Financial strain involved the participant reporting whether they had to go without things they or their family really needed in the last year due to being short of money (sometimes/often).

- Medication use: Participants reported on their current medication use, including medication for blood pressure, anxiety and depression, sleep problems, memory problems, cholesterol, contraception, hormone replacement therapy, pain relief or other any problems. All variables were coded to reflect current use/not, aside from use of pain relief medication which was coded to reflect weekly (or more frequent) use due to its overall frequency. 


\section{Data analysis}

This study describes the characteristics of persistent frequent GP attenders. Initially, we report the pattern of frequent GP service use across the three waves and evaluate consistency in patterns of frequent attendance over time using log-linear analysis. We describe patterns of GP service use within the overall sample. A series of univariate analyses are used to identify factors that differentiate non-FAs, occasional FAs (one wave or two waves not consecutive) and persistent FAs (two wave or more consecutive frequent attendance). From this, significant factors were analysed using two simple logistic regression models to determine what differentiated (1) between non-FAs and individuals who were FAs at any wave; and (2) between occasional and persistent FAs. Finally, the unique contribution of factors was examined in two multivariate logistic regression models with backwards elimination of non-significant terms. Missing data were minimal. The majority $(74 \%)$ of covariates examined in the univariate analyses have no missing data. For the other covariates, between $0.06 \%$ and $0.98 \%$ of cases were missing. Hence, missing data were excluded on a case-by-case basis.

\section{RESULTS}

A preliminary analysis showed that gender was the only covariate significantly associated with baseline consent to data linkage (females more likely to consent to data linkage than males, $\mathrm{p}<0.01)$. Given the interest in continuity of service use over time, analysis is restricted to participants with survey and linked administrative data across all three waves $(\mathrm{n}=1734)$. Analysis confirmed that neither number of GP consultations nor identification as a FA at wave 1 was associated with subsequent attrition. A multivariate model showed that only baseline non-smoking status $(p<0.001)$, higher (tertiary) educational qualifications $(\mathrm{p}<0.001)$ and working (vs unemployment or non-participation in the labour force; $\mathrm{p}=0.008$ ) were associated with increased likelihood of retention and consent to data linkage in subsequent waves of data collection.

Figure 1 reports the classification of respondents to FA categories over the three waves. In each of the three waves, the percentage of respondents identified as FAs was $8.4 \%, 7.0 \%$ and $8.4 \%$. Across the three waves, just over $1 / 5$ th of respondents $(n=328 ; 18.9 \%)$ were FAs at one (or more) time points. Although the absolute number of persistent FAs was small, log-linear analysis showed that the consistency in FA status (ie, both the number of persistent FAs and never FAs) was greater than what would be expected if there was no association between frequent attendance over time $\left(\chi^{2}=226.90\right.$, $\mathrm{p}<0.001)$. Among the 1734 respondents, $62(3.6 \%)$ were persistent FAs at all three waves, $266(15.3 \%)$ were occasional FAs and 1406 (81.1\%) were consistently not FAs.

On average, at baseline, non-FAs had 2.9 GP consultations during the 12-month period $(\mathrm{SE}=0.06, \mathrm{IQR}=1-4$, median=2) while FAs had on average 13.4 consultations $(\mathrm{SE}=0.52, \mathrm{IQR}=9-14$, median=11). At baseline, those identified as occasional FAs had an average of 7.4 consultations $(\mathrm{SE}=0.17, \mathrm{IQR}=3-10$, median=7) while persistent FAs had an average of 12.3 consultations $(\mathrm{SE}=0.58$, $\mathrm{IQR}=7-16$, median $=10)$. At wave 1 , FAs $(8.4 \%$ of the population) were responsible for $33.4 \%$ of all GP consultations. Those identified as persistent FAs $(3.6 \%$ of the population) were responsible for $12.5 \%$ of consultations at wave 1 , and across the three waves were responsible for $15.5 \%$ of all GP consultations.

Table 1 presents the baseline characteristics of non-FAs, occasional FAs (no consecutive waves of frequent attendance) and persistent FAs (two wave or more consecutive frequent attendance). Owing to the number of variables considered, only effects which reached the $\mathrm{p}=0.001$ level are interpreted. As likelihood of frequent attendance increased, so did the likelihood of being female and suffering diabetes, asthma, thyroid problems, arthritis, and heart conditions. Increasing likelihood of frequent attendance was associated with more somatic symptoms (headaches, dizzy spells and sleep problems), elevated levels of health anxiety, depression symptoms, higher levels of rumination, lower levels of mastery and a greater number of stressful life events. Self-reported health and reports that health interfered with everyday activities increased with increasing attendance, as did the likelihood of not participating in employment and reported financial pressure. Finally, increased likelihood of frequent attendance was also associated with

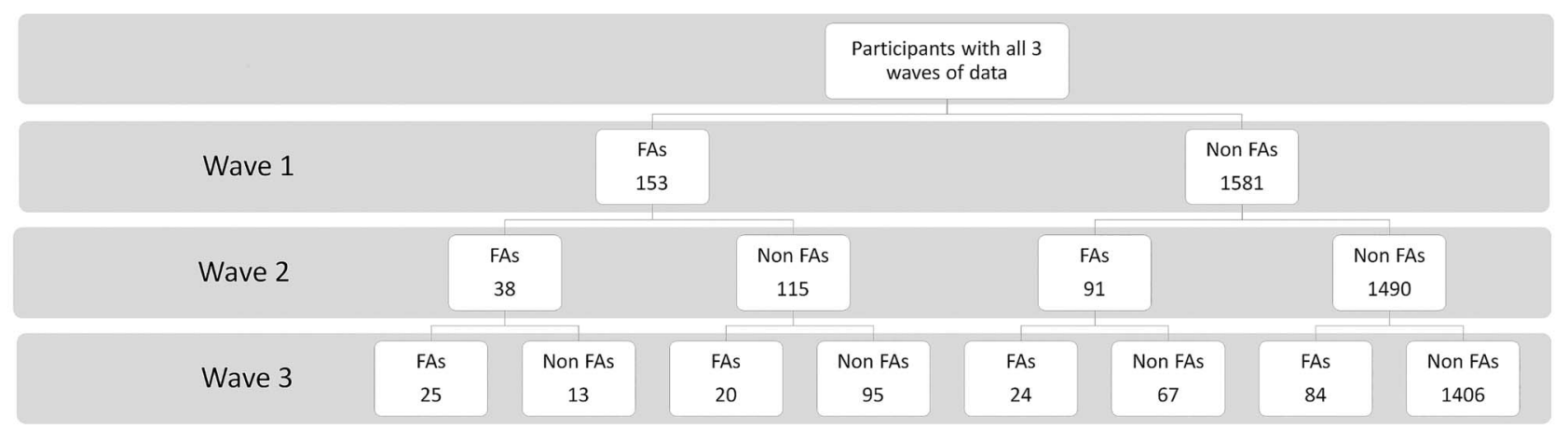

Figure 1 Frequent attender (FA) status at each wave for participants who have data for all three waves. 
Table 1 Describing non-FAs as compared with FAs who are occasional (one or two waves not consecutive) and persistent FAs (two waves or more consecutive frequent attendance)

\begin{tabular}{|c|c|c|c|c|}
\hline & Non-FA & Occasional FA & Persistent FA & Test of significance \\
\hline Number & 1406 & 266 & 62 & \\
\hline Gender (women) & $51.3 \%$ & $66.5 \%$ & $75.8 \%$ & $\chi^{2}=32.78, p<0.001$ \\
\hline \multicolumn{5}{|l|}{ Morbidity } \\
\hline Diabetes & $0.7 \%$ & $4.9 \%$ & $14.5 \%$ & $\chi^{2}=78.52, p<0.001$ \\
\hline Asthma & $10.4 \%$ & $17.3 \%$ & $30.6 \%$ & $\chi^{2}=30.53, p<0.001$ \\
\hline Thyroid & $2.1 \%$ & $7.1 \%$ & $11.3 \%$ & $\chi^{2}=31.3, p<0.001$ \\
\hline Arthritis & $8.3 \%$ & $13.9 \%$ & $25.8 \%$ & $\chi^{2}=26.52, p<0.001$ \\
\hline Heart & $2.6 \%$ & $1.9 \%$ & $11.3 \%$ & $\chi^{2}=17.73, p<0.001$ \\
\hline Cataracts & $2.6 \%$ & $3.0 \%$ & $3.2 \%$ & $\chi^{2}=0.025, p=0.88$ \\
\hline Hypertension & $24.6 \%$ & $23.9 \%$ & $32.4 \%$ & $\chi^{2}=0.80, p=0.37$ \\
\hline Cancer & $1.4 \%$ & $3.8 \%$ & $0 \%$ & $\chi^{2}=8.32, p=0.016$ \\
\hline Epilepsy & $0.8 \%$ & $0.7 \%$ & $1.6 \%$ & $\chi^{2}=1.72, p=0.63$ \\
\hline Stroke & $0.9 \%$ & $1.1 \%$ & $3.3 \%$ & $\chi^{2}=3.18, p=0.20$ \\
\hline \multicolumn{5}{|l|}{ Mental health and personality } \\
\hline Headaches and neckaches & $48.8 \%$ & $58.5 \%$ & $65.6 \%$ & $\chi^{2}=13.87, p=0.001$ \\
\hline Trembling, tingling, dizzy spells, etc & $19.8 \%$ & $36.2 \%$ & $39.3 \%$ & $\chi^{2}=43.29, p<0.001$ \\
\hline Worried about health & $26.9 \%$ & $46.8 \%$ & $62.3 \%$ & $\chi^{2}=69.63, p<0.001$ \\
\hline Difficulty falling asleep & $25.8 \%$ & $36.6 \%$ & $52.5 \%$ & $\chi^{2}=30.71, p<0.001$ \\
\hline Depression & $M=2.11, S E=0.06$ & $\mathrm{M}=3.21, \mathrm{SE}=0.16$ & $\mathrm{M}=4.59, \mathrm{SE}=0.35$ & $F(1728)=57.94, p<0.001$ \\
\hline Rumination & $M=8.29, S E=0.11$ & $\mathrm{M}=10.09, \mathrm{SE}=0.33$ & $M=11.03, S E=1.11$ & $F(1729)=28.13, p<0.001$ \\
\hline Mastery & $M=22.3, S E=0.09$ & $\mathrm{M}=21.14, \mathrm{SE}=0.23$ & $M=20.30, S E=0.75$ & $F(1728)=14.28, p<0.001$ \\
\hline \multicolumn{5}{|c|}{ ( } \\
\hline 0 & $41.1 \%$ & $31.9 \%$ & $25.8 \%$ & $\chi^{2}=44.12, p<0.001$ \\
\hline 1 & $26.6 \%$ & $25.6 \%$ & $12.9 \%$ & \\
\hline 2 & $17.6 \%$ & $21.8 \%$ & $19.3 \%$ & \\
\hline $3+$ & $14.7 \%$ & $20.7 \%$ & $41.9 \%$ & \\
\hline \multicolumn{5}{|l|}{ Self-reported physical health } \\
\hline General Health (poor) & $0.4 \%$ & $1.9 \%$ & $16.1 \%$ & $\chi^{2}=123.55, p<0.001$ \\
\hline Limit moderate activity (any) & $12.4 \%$ & $26.3 \%$ & $45.2 \%$ & $\chi^{2}=75.10, p<0.001$ \\
\hline Limit stairs (any) & $17.2 \%$ & $33.8 \%$ & $53.2 \%$ & $\chi^{2}=77.25, p<0.001$ \\
\hline Accomplish less (yes) & $13.3 \%$ & $30.1 \%$ & $46.8 \%$ & $\chi^{2}=84.54, p<0.001$ \\
\hline Limited work kind (yes) & $11.2 \%$ & $26.3 \%$ & $45.2 \%$ & $\chi^{2}=88.47, p<0.001$ \\
\hline Pain interfere (any) & $35.0 \%$ & $54.9 \%$ & $67.7 \%$ & $\chi^{2}=59.09, p<0.001$ \\
\hline \multicolumn{5}{|l|}{ Sociodemographics } \\
\hline \multicolumn{5}{|l|}{ Labour force status } \\
\hline Employed & $92.2 \%$ & $88.7 \%$ & $74.2 \%$ & $\chi^{2}=25.93, p<0.001$ \\
\hline Unemployed & $1.9 \%$ & $2.6 \%$ & $6.4 \%$ & \\
\hline Not in labour force & $5.8 \%$ & $8.6 \%$ & $19.3 \%$ & \\
\hline Child 15 under & $67.7 \%$ & $62.8 \%$ & $54.8 \%$ & $\chi^{2}=6.36, p=0.042$ \\
\hline \multicolumn{5}{|l|}{ Education } \\
\hline Not secondary & $25.7 \%$ & $25.6 \%$ & $38.7 \%$ & $\chi^{2}=5.60, p=0.231$ \\
\hline Secondary & $20.6 \%$ & $19.9 \%$ & $19.3 \%$ & \\
\hline Tertiary & $53.7 \%$ & $54.5 \%$ & $41.9 \%$ & \\
\hline Financial pressure (yes) & $23.9 \%$ & $31.9 \%$ & $50.0 \%$ & $\chi^{2}=26.64, p<0.001$ \\
\hline \multicolumn{5}{|l|}{ Medication use (types) } \\
\hline Blood pressure & $4.3 \%$ & $8.6 \%$ & $16.1 \%$ & $\chi^{2}=23.13, p<0.001$ \\
\hline Antidepressants/anxiolytics & $7.4 \%$ & $21.0 \%$ & $33.9 \%$ & $\chi^{2}=82.38, p<0.001$ \\
\hline Sleep problems & $10.5 \%$ & $20.7 \%$ & $40.3 \%$ & $\chi^{2}=61.76, p<0.001$ \\
\hline Memory problems & $1.8 \%$ & $2.6 \%$ & $8.06 \%$ & $\chi^{2}=10.98, p=0.004$ \\
\hline Pain relief & $9.5 \%$ & $18.8 \%$ & $43.5 \%$ & $\chi^{2}=77.21, p<0.001$ \\
\hline Other medication & $23.0 \%$ & $35.7 \%$ & $53.2 \%$ & $\chi^{2}=43.62, p<0.001$ \\
\hline
\end{tabular}

FA, frequent attenders.

increased use of all types of medication, apart from memory medication.

To identify the source of these differences, two sets of simple logistic regression models compared non-FAs and those who were FAs at any point, and those who were occasional (non-consecutive) FAs to those who were classified as persistent FAs (see table 2). All included variables differentiated non-FAs from any FAs, apart from 
Table 2 Ordinal logistic regression models examining what factors are related to being a non-FA or any type of FA (any FA: one, two or three waves) and occasional FAs (one or two waves not consecutive), and persistent FAs (two waves or more consecutive frequent attendance)

\begin{tabular}{|c|c|c|c|c|c|c|}
\hline & \multicolumn{3}{|c|}{ Non-FA vs any FA } & \multicolumn{3}{|c|}{ Occasional FA vs persistent FA } \\
\hline & $\overline{\text { OR }}$ & $95 \% \mathrm{Cl}$ & sig & $\overline{\mathrm{OR}}$ & $95 \% \mathrm{Cl}$ & sig \\
\hline Gender (women) & 2.05 & 1.77 to 2.37 & $<0.001$ & 1.57 & 1.09 to 2.27 & 0.015 \\
\hline \multicolumn{7}{|l|}{ Morbidity } \\
\hline Diabetes & 10.04 & 4.70 to 21.41 & $<0.001$ & 3.30 & 1.34 to 8.13 & 0.009 \\
\hline Asthma & 2.13 & 1.55 to 2.94 & $<0.001$ & 2.11 & 1.13 to 3.95 & 0.019 \\
\hline Thyroid & 3.95 & 2.30 to 6.77 & $<0.001$ & 1.65 & 0.66 to 4.13 & 0.281 \\
\hline Arthritis & 4.22 & 1.50 to 3.01 & $<0.001$ & 2.15 & 1.10 to 4.19 & 0.024 \\
\hline Heart & 1.44 & 0.74 to 2.81 & 0.278 & 6.64 & 2.03 to 21.70 & 0.002 \\
\hline \multicolumn{7}{|l|}{ Mental health and personality } \\
\hline Headaches and neckaches & 1.56 & 1.22 to 2.00 & $<0.001$ & 1.35 & 0.75 to 2.42 & 0.310 \\
\hline Trembling, tingling, dizzy spells, etc & 2.35 & 1.81 to 3.06 & $<0.001$ & 1.14 & 0.64 to 2.02 & 0.649 \\
\hline Worried about health & 2.68 & 2.10 to 3.44 & $<0.001$ & 1.88 & 1.06 to 3.33 & 0.031 \\
\hline Difficulty falling asleep & 1.88 & 1.46 to 2.42 & $<0.001$ & 1.91 & 1.09 to 3.35 & 0.024 \\
\hline Depression & 1.26 & 1.20 to 1.33 & $<0.001$ & 1.21 & 1.09 to 1.34 & $<0.001$ \\
\hline Rumination & 1.10 & 1.07 to 1.13 & $<0.001$ & 1.03 & 0.98 to 1.08 & 0.234 \\
\hline Mastery & 0.89 & 0.86 to 0.93 & $<0.001$ & 0.95 & 0.88 to 1.02 & 0.129 \\
\hline Life events & 1.27 & 1.19 to 1.35 & $<0.001$ & 1.25 & 1.08 to 1.43 & 0.002 \\
\hline \multicolumn{7}{|l|}{ Self-reported physical health } \\
\hline General health (poor) & 11.18 & 4.30 to 29.05 & $<0.001$ & 10.04 & 3.29 to 30.58 & $<0.001$ \\
\hline Limit moderate activity (any) & 3.02 & 2.27 to 4.01 & $<0.001$ & 2.30 & 1.30 to 4.08 & 0.004 \\
\hline Limit stairs (any) & 2.88 & 2.22 to 3.75 & $<0.001$ & 2.22 & 1.27 to 3.89 & 0.005 \\
\hline Accomplish less (yes) & 0.31 & 0.23 to 0.41 & $<0.001$ & 0.49 & 0.28 to 0.86 & 0.013 \\
\hline Limited work kind (yes) & 0.29 & 0.22 to 0.39 & $<0.001$ & 0.43 & 0.24 to 0.77 & 0.004 \\
\hline Pain interfere (any) & 2.49 & 1.95 to 3.19 & $<0.001$ & 1.73 & 0.96 to 3.10 & 0.067 \\
\hline \multicolumn{7}{|l|}{ Sociodemographics } \\
\hline \multicolumn{7}{|l|}{ Labour force status (employed) } \\
\hline Unemployed & 1.87 & 0.92 to 3.82 & 0.084 & 2.93 & 0.82 to 10.42 & 0.097 \\
\hline Not in labour force & 1.96 & 1.29 to 2.98 & $<0.001$ & 2.68 & 1.24 to 5.76 & 0.012 \\
\hline Financial pressure (yes) & 1.74 & 1.35 to 2.25 & $<0.001$ & 2.13 & 1.21 to 3.73 & 0.008 \\
\hline \multicolumn{7}{|l|}{ Medication use (types) } \\
\hline Blood pressure & 2.51 & 1.61 to 3.91 & $<0.001$ & 2.03 & 0.91 to 4.52 & 0.083 \\
\hline Antidepressants/anxiolytics & 3.84 & 2.78 to 5.31 & $<0.001$ & 1.92 & 1.05 to 3.51 & 0.034 \\
\hline Sleep problems & 2.74 & 2.02 to 3.72 & $<0.001$ & 2.59 & 1.44 to 4.67 & 0.001 \\
\hline Pain relief & 2.91 & 2.13 to 3.97 & $<0.001$ & 3.33 & 1.85 to 6.00 & $<0.001$ \\
\hline Other medication & 2.14 & 1.66 to 2.77 & $<0.001$ & 2.05 & 1.17 to 3.58 & 0.012 \\
\hline
\end{tabular}

heart disease and employment status. In contrast, only depression, self-reported general health, use of sleep medications and pain relief differentiated occasional and persistent FAs at the $\mathrm{p} \leq 0.001$ level.

Finally, to identify the unique risk factors associated with frequent attendance, and that differentiate between occasional and persistent FAs, two multivariate logistic regression models were conducted. Starting with the factors identified as significant in the simple models, backwards elimination was used to remove covariates from the model which did not significantly contribute to the prediction (at $\mathrm{p}<0.05)$. The model results in table 3 demonstrate that gender, sociodemographic characteristics, chronic physical conditions, mental health, aspects of self-rated health and some medication use differentiated FAs from non-FAs. In contrast, gender, fewer chronic conditions, mental health, personality (rumination) and a single item assessing the impact of health on activity differentiated occasional and persistent FAs.

\section{DISCUSSION}

\section{Summary of aims and findings}

Although there was an association between frequent attendance across time, only a small number of patients were identified as persistent FAs across consecutive waves of data collection. However, frequent attendance was not uncommon, with around a fifth of all respondents identified as FAs at some point during the study period. The analysis sought to identify the characteristics at baseline that differentiated FAs from non-FAs and those FAs identified as persistent. Unsurprisingly, there were a large number of factors which were important to the different 
Table 3 Multivariate logistic regression to examine the unique contribution of factors to the difference between non-FA or any type of FA (any FA: one, two or three waves) and occasional FAs (one or two waves not consecutive), and persistent FAs (two waves or more consecutive frequent attendance)

\begin{tabular}{|c|c|c|c|c|c|c|}
\hline & \multicolumn{3}{|c|}{ Non-FA vs any FA } & \multicolumn{3}{|c|}{ Occasional FA vs persistent FA } \\
\hline & $\overline{\text { OR }}$ & p Value & $95 \% \mathrm{Cl}$ & $\overline{\text { OR }}$ & p Value & $95 \% \mathrm{Cl}$ \\
\hline Gender (women) & 1.71 & $<0.001$ & 1.45 to 2.02 & 1.67 & 0.015 & 1.11 to 2.52 \\
\hline \multicolumn{7}{|l|}{ Morbidity } \\
\hline Diabetes & 3.95 & $<0.001$ & 2.70 to 5.79 & 2.53 & 0.001 & 1.45 to 4.41 \\
\hline Asthma & 1.64 & $<0.001$ & 1.32 to 2.03 & 1.99 & 0.001 & 1.33 to 2.97 \\
\hline Thyroid & 1.70 & 0.001 & 1.23 to 2.33 & & & \\
\hline Arthritis & 1.38 & 0.002 & 1.13 to 1.68 & & & \\
\hline Heart & & & & 1.90 & 0.063 & 0.97 to 3.74 \\
\hline \multicolumn{7}{|l|}{ Mental health and personality } \\
\hline Depression & 1.10 & $<0.001$ & 1.06 to 1.14 & 1.13 & 0.011 & 1.03 to 1.24 \\
\hline Rumination & & & & 0.96 & 0.049 & 0.92 to 1.00 \\
\hline \multicolumn{7}{|l|}{ Self-reported physical health } \\
\hline General health (poor) & 2.11 & 0.016 & 1.15 to 3.86 & & & \\
\hline Limit moderate activity (any) & & & & 1.67 & 0.009 & 1.14 to 2.45 \\
\hline Accomplish less (yes) & 0.72 & 0.001 & 0.59 to 0.87 & & & \\
\hline Pain interfere (any) & 1.40 & $<0.001$ & 1.18 to 1.67 & & & \\
\hline \multicolumn{7}{|l|}{ Sociodemographics } \\
\hline \multicolumn{7}{|l|}{ Labour force status (employed) } \\
\hline Unemployed & 1.30 & 0.295 & 0.79 to 2.14 & & & \\
\hline Not in labour force & 1.37 & 0.025 & 1.04 to 1.80 & & & \\
\hline Financial pressure (yes) & 1.33 & 0.002 & 1.11 to 1.60 & & & \\
\hline \multicolumn{7}{|l|}{ Medication use (types) } \\
\hline Blood pressure & 1.73 & $<0.001$ & 1.38 to 2.18 & & & \\
\hline Antidepressants/anxiolytics & 2.11 & $<0.001$ & 1.70 to 2.63 & 1.69 & 0.013 & 1.12 to 2.57 \\
\hline Sleep problems & 1.40 & 0.002 & 1.13 to 1.73 & 1.66 & 0.016 & 1.10 to 2.51 \\
\hline Pain relief & & & & 1.97 & 0.001 & 1.33 to 2.91 \\
\hline Other medication & 1.79 & $<0.001$ & 1.51 to 2.12 & & & \\
\hline
\end{tabular}

attendance patterns. However, there were a greater number of risk factors which differentiated non-attenders from FAs than between occasional and persistent FAs. Not all chronic physical conditions were important to the understanding the consistency of frequent attendance: diabetes, asthma thyroid problem and arthritis were associated with the distinction between non-FAs and FAs, while heart disease was important for differentiating the types of FAs. Similarly, we found that health anxiety, rumination, mastery and life events differentiated non-FAs from FAs, while only depression was important to this distinction as well as the difference between the types of FAs. Further medication use was associated with the distinction between being a FA and not, but pain relief frequency also increased with persistent FAs over occasional FAs. FAs were found to be more likely to be not in the work force and suffered more financial strain, consistent with the international evidence on the important role of social disadvantage. ${ }^{12} 16 \quad 17$ Further, women were also more likely to be FAs than their male counterparts.

The association between medication use and persistent frequent attendance is difficult to interpret. At one level, medication use may also be a marker of morbidity. Alternatively, the association between frequent attendance and medication use may be related to consultations to facilitate repeated prescriptions. Consistent with previous research, our results show that Australians who report elevated depression, somatic and health anxiety symptoms (together with higher levels of rumination and low mastery) are more likely to be FAs. ${ }^{21} 23$ This may, in part, reflect somatising or medically unexplained symptoms. FAs rated their health poorer across a range of domains including general health, and much greater impairment, including pain. The international literature shows persistent users report increased somatisation. $^{1623}$

\section{Caveats to interpretation}

While we have identified a range of individual characteristics associated with the likelihood of occasional and persistent frequent attendance in primary care, we are not suggesting that these are the only determinants of health service use and recognise the influence of factors beyond the individual patient and their circumstances. Rates of GP attendance can also reflect the nature of the healthcare system, the intersection between health prevention, primary and tertiary care, broader social and cultural factors that may differ within and between countries, patient to GP communication and 
characteristics of the health professional. ${ }^{7} 3132$ Studies like the current are not able to explore these issues and do make an important contribution through consideration of a diverse range of patient characteristics. It is, nonetheless, important to recognise the limitations of this type of research and not buy into the myth that frequent attendance is entirely a patient's responsibility.

\section{Limitations and strengths of this study}

A unique contribution of this study lies in the linkage of longitudinal representative survey data, with the objectivity of linked administrative data. Unlike other studies which rely on retrospective reports of health service use, this allowed identification of persistent users over an 8-year period without sampling or self-report bias.

However, the current study is limited by our focus on a mid-aged cohort, which may explain the limited role of chronic physical conditions. Further, generalisability may be limited as the sample is drawn from residents of the Canberra region which has been shown to have a relatively low proportion of FAs. ${ }^{10}$ Finally, while the use of linked Medicare data provide an objective marker of health service use, it does not cover all potential primary care consultations (eg, excluding Department of Veterans' Affairs beneficiaries and some patients receiving services under compensation agreements). It is important to note that the current study included selfreport chronic physical conditions which has been found to differ from conditions and sickness reported by a physician. However, studies have shown the predictive utility of self-report morbidity ${ }^{33}$ and that self-reported disability has shown greater predictability of morbidity 10 years later. ${ }^{34}$ It should be noted, however, that health condition and levels of educational attainment have been shown to impact the accuracy of self-reported morbidity, ${ }^{35}$ and hence this may generate a different pattern of results.

\section{Future directions}

The current study does not assess the transitions between FA status over time or the causality of the relationships. Research is needed to understand the longitudinal nature of frequent attendance, the factors that drive frequent attendance and potential strategies to reduce unnecessary attendance and cut costs. Smits et at suggests that future research needs to investigate the aetiology of (the persistence of) frequent attendance, with a focus on personality factors, life events and socioeconomic circumstances, potentially critical determinants of attendance and costs. As a first step, this study described persistence in an Australian sample with a diverse set of factors examined. Future research will examine the longitudinal relationship between the factors highlighted and attendance and investigate temporal ordering and potentially the causal nature of the relationships.

\section{CONCLUSION}

The current study provides novel insights into the persistence of frequent attendance, and the characteristics of persistent FAs. The current study suggests that there is considerable variability in the classification of FAs over time, and that FAs are characterised by greater morbidity, including psychiatric and psychological symptomatology and impairment in activities of daily living. The results suggest that mental health and psychological processes are important to better understanding the attendance patterns of FAs and may be a key to effective intervention.

Acknowledgements The authors thank the study participants, PATH Interviewers, Karen Maxwell and Trish Jacomb; and the other PATH Chief Investigators: Kaarin Anstey, Helen Christensen, Anthony Jorm, Bryan Rodgers, Andrew Mackinnon, Simon Easteal and Nicolas Cherbuin.

Contributors CP analysed and interpreted data under the supervision of PB. $\mathrm{CP}$ and $\mathrm{PB}$ worked together on drafting, revising and approving final version of the work.

Funding PB is funded by Australian Research Council (ARC) Future Fellowship \#FT13101444. The PATH Through Life Study is funded by National Health and Medical Research Council Grants 973302, 179805 and 418039.

Competing interests None declared.

Ethics approval Human Research Ethics Committee of The Australian National University.

Provenance and peer review Not commissioned; externally peer reviewed.

Data sharing statement Data for the study are from the PATH Through Life 40s cohort. Further information including a list of publications is available at http://crahw.anu.edu.au/research/projects/personality-total-health-paththrough-life. Strategic collaborations are welcome and contact information is available on the website for interested parties to learn more about formal application procedures.

Open Access This is an Open Access article distributed in accordance with the Creative Commons Attribution Non Commercial (CC BY-NC 4.0) license, which permits others to distribute, remix, adapt, build upon this work noncommercially, and license their derivative works on different terms, provided the original work is properly cited and the use is non-commercial. See: http:// creativecommons.org/licenses/by-nc/4.0/

\section{REFERENCES}

1. OECD. What future for health spending. OECD Economics Department Policy Notes, No. 19, 2013.

2. The Commonwealth of Australia. 2015 Intergenerational Report: Australia in 2055, 2015. http://www.treasury.gov.au/ /media/ Treasury/Publications\%20and\%20Media/Publications/2015/2015\% 20Intergenerational\%20Report/Downloads/PDF/2015_IGR.ashx

3. Commonwealth of Australia. Budget 2014-15 Health 2014. http:// budget.gov.au/2014-15/content/glossy/health/download/Health.pdf

4. Commission of Audit. Towards Responsible Government, 2014.

5. Vedsted $\mathrm{P}$, Christensen MB. Frequent attenders in general practice care: a literature review with special reference to methodological considerations. Public Health 2005;119:118-37.

6. Gill D, Sharpe M. Frequent consulters in general practice: a systematic review of studies of prevalence, associations and outcome. J Psychosom Res 1999;47:115-30.

7. Neal RD, Heywood PL, Morley S, et al. Frequency of patients consulting in general practice and workload generated by frequent attenders: comparisons between practices. $\mathrm{Br} J$ Gen Pract 1998;48:895-8.

8. Heywood PL, Blackie GC, Cameron IH, et al. An assessment of the attributes of frequent attenders to general practice. Fam Pract 1998;48:895-8.

9. Smits FT, Brouwer $\mathrm{HJ}$, Zwinderman $\mathrm{AH}$, et al. Morbidity and doctor characteristics only partly explain the substantial healthcare 
expenditures of frequent attenders: a record linkage study between patient data and reimbursements data. BMC Fam Pract 2013;14:138.

10. National Health Performance Authority. Healthy Communities: Frequent GP attenders and their use of health services in 20122013, 2015. http://www.myhealthycommunities.gov.au/our-reports/ frequent-gp-attenders-use-health-services/march-2015

11. Corney R, Murray J. The characteristics of high and low attenders at two general practices. Soc Psychiatry Psychiatr Epidemiol 1988;23:39-48.

12. Scaife B, Gill P, Heywood PL, et al. Socio-economic characteristics of adult frequent attenders in general practice: secondary analysis of data. Fam Pract 2000;17:298-304

13. Smits FT, Mohrs J, Beem EE, et al. Defining frequent attendance in general practice. BMC Fam Pract 2008;9:21.

14. Howe A, Parry G, Pickvance D, et al. Defining frequent attendance: evidence for routine age and sex correction in studies from primary care settings. Br J Gen Pract 2002;52:561-2.

15. Foster $\mathrm{A}$, Jordan $\mathrm{K}$, Croft $\mathrm{P}$. Is frequent attendance in primary care disease-specific? Fam Pract 2006;23:444-52.

16. Gili M, Luciano JV, Serrano MJ, et al. Mental disorders among frequent attenders in primary care: a comparison with routine attenders. J Nerv Ment Dis 2011;199:744-9.

17. Diaz E, Gimeno-Feliu L-A, Calderon-Larranaga A, et al. Frequent attenders in general practice and immigrant status in Norway: a nationwide cross-section study. Scan J Prim Health Care 2014;32:232-40.

18. Vedsted $P$, Olesen $F$. Social environment and frequent attendance in Danish general practice. Br J Gen Pract 2005;55:510-15.

19. Vedsted P, Fink P, Olesen F, et al. Psychological distress as a predictor of frequent attendance in family practice: a cohort study. Psychosomatics 2001;42:416-22.

20. Jyvasjarvi S, Joukamaa M, Vaisanen $\mathrm{E}$, et al. Somatizing frequent attenders in primary health care. J Psychosom Res 2001;50:185-92.

21. Smits FT, Brouwer $\mathrm{HJ}$, Zwinderman $\mathrm{AH}$, et al. Why do they keep coming back? Psychosocial etiology of persistence of frequent attendance in primary care: a prospective cohort study. $J$ Psychosom Res 2014;77:492-503.

22. Carney TA, Guy S, Jeffery G. Frequent attenders in general practice: a retrospective 20 -year follow-up study. Br J Gen Pract 2001;51:567-9.
23. Smits FT, Brouwer HJ, Ter Riet G, et al. Epidemiology of frequent attenders: a 3-year historic cohort study comparing attendance, morbidity and prescriptions of one-year and persistent frequent attenders. BMC Public Health 2009;9:36.

24. Knox SA, Britt H. The contribution of demographic and morbidity factors to self-reported visits frequency of patients: a cross-sectional study of general practice patients in Australia. BMC Fam Pract 2004;5:17

25. Anstey KJ, Christensen $\mathrm{H}$, Butterworth $\mathrm{P}$, et al. Cohort profile: the PATH through life project. Int J Epidemiol 2012;41:951-60.

26. Ware JE, Kosinski M, Keller SD. A 12-item short-form health survey. Med Care 1996;34:220-33.

27. Goldberg D, Bridges K, Duncan-Jones $\mathrm{P}$, et al. Detecting anxiety and depression in general medical settings. BMJ 1988;297: 897-9.

28. Pearlin L, Lieberman M, Menaghan E, et al. The stress process. $J$ Health Soc Behav 1981;22:337-56.

29. Nolen-Hoeksema A, Parker L, Larson J. Ruminative coping with depressed mood following loss. J Pers Soc Psycho 1994;67:92-104.

30. Brugha TS, Cragg D. The list of threatening experiences: the reliability and validity of a brief life events questionnaire. Acta Psychiatr Scand 1990;82:77-81.

31. Salmon P, Peters S, Clifford R, et al. Contrasts between general practitioners who consent and decline training to improve the management of medically unexplained symptoms. J Gen Intern Med 2007;22:565-71.

32. Reid S, Whooley D, Crayford T, et al. Medically unexplained symptoms; GP's attitudes towards their cause and management. Fam Pract 2001;18:519-23.

33. Martin LM, Leff M, Calonge $\mathrm{N}$, et al. Validation of self-reported chronic conditions and health services in a managed care population. Am J Prev Med 2000;18:215-18.

34. Ferraro KF, Su Y. Physician-evaluated and self-reported morbidity for predicting disability. Am J Public Health 2000;90: 103-8.

35. Bergmann MM, Byers T, Freedeman DS, et al. Validity of self-reported diagnoses leading to hospitalization: a comparison of self-reports with hospital records in a prospective study of American adults. Am J Epidemiol 1998;147:969-77. 